\title{
La investigación etnográfica en los estudios de patrimonio: curso del Incipit sobre el trabajo de campo
}

\begin{abstract}
El curso de especialización en el trabajo de campo etnográfico para profesionales del patrimonio, organizado por el Instituto de Ciencias del Patrimonio (perteneciente al CSIC), convoca su tercera edición para la última semana de octubre de 2017. Este curso nace ante la creciente demanda de formación en metodología de recogida de datos cualitativos en las investigaciones etnográficas, y se oferta con la convicción de que este tipo de investigaciones es capaz de acceder a rincones que de otro modo podrían quedar inexplorados.
\end{abstract}

José Muñoz-Albaladejo, Cristina Sánchez-Carretero | Instituto de Ciencias del Patrimonio (INCIPIT), Consejo Superior de Investigaciones Científicas (CSIC)

Guadalupe Jiménez-Esquinas | Universidade de Santiago de Compostela

URL de la contribución <www.iaph.es/revistaph/index.php/revistaph/article/view/3988>

El Instituto de Ciencias del Patrimonio (Incipit), perteneciente al Consejo Superior de Investigaciones Científicas (CSIC) y ubicado en Santiago de Compostela, organiza durante la última semana del mes de octubre la tercera edición del Curso de Especialización del CSIC de Trabajo de Campo Etnográfico para Profesionales del Patrimonio.

Se trata de un curso presencial codirigido por las antropólogas Cristina Sánchez-Carretero (Incipit) y Guadalupe Jiménez-Esquinas (Universidade de Santiago de Compostela) e impartido por un grupo de seis docentes. Este curso va dirigido tanto a personas licenciadas o graduadas de cualquier disciplina propia de las humanidades, las ciencias sociales o las ciencias naturales, como a profesionales de ámbitos vinculados al patrimonio y las industrias culturales y tiene como objetivo principal dotar al alumnado de un conocimiento teórico y práctico sobre las principales técnicas del trabajo de campo etnográfico. Esto se lleva a cabo a través de siete módulos en los que se trata de explicar en qué consiste una investigación etnográfica, adentrándonos en la observación participante como situación metodológica, e incluyendo técnicas que van desde la elaboración del diario de campo hasta las cartografías colectivas, pasando por las historias de vida y las entrevistas personales, entre otras.

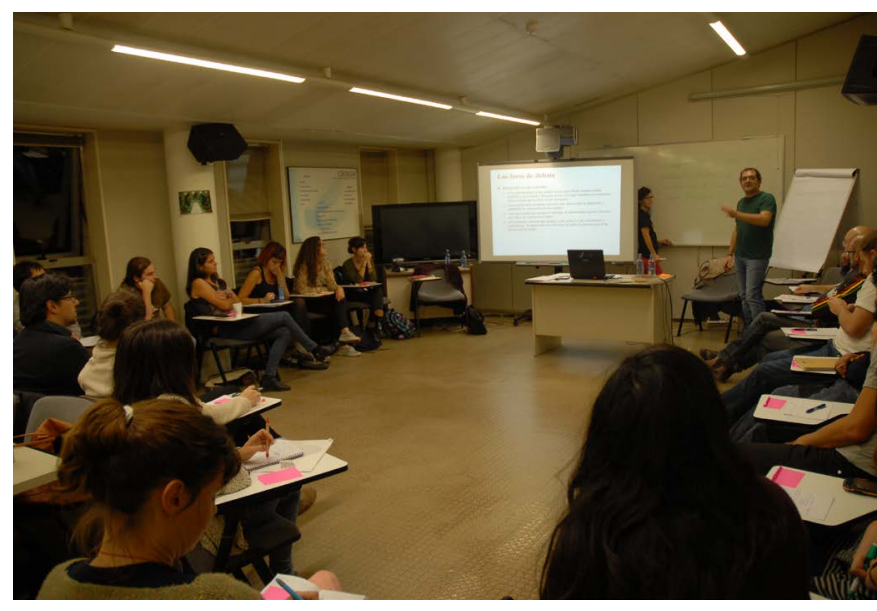

Sesión del curso dedicada a IAP | foto Cristina Sánchez-Carretero

El curso surge como respuesta a una creciente demanda de este tipo de metodologías de recogida de datos cualitativos, cada vez más utilizadas en investigaciones y proyectos vinculados al patrimonio desde diferentes disciplinas como la arqueología, la arquitectura, el turismo o el medio ambiente. Teniendo en cuenta esta necesidad, en este curso de especialización queremos ofrecer una iniciación al ámbito de la investigación etnográfica, orientándonos a la formación de profesionales y estudiantes en una serie de conocimientos teóricos y unas capacidades prácticas que sean fácilmente aplicables. En el 
Instituto de Ciencias del Patrimonio colaboramos investigadoras de ámbitos diversos, provenientes especialmente de los campos de la arqueología y la antropología, y consideramos que la formación en los rudimentos de la investigación etnográfica puede resultar útil a la hora de aportar una visión diferente a profesionales de cualquier disciplina, ya que permite profundizar en los temas de estudio a través de la toma en consideración de las realidades empíricas que van más allá de la superficialidad en la que, en ocasiones, se queda la investigación cuantitativa, obviando contextos en situaciones en las que los objetos o sujetos de estudio están ampliamente influenciados por estos, algo que cobra especial importancia en los estudios patrimoniales.

En este sentido, podríamos decir que la motivación para realizar este curso parte también de la creencia de que la investigación etnográfica es capaz de acceder a rincones que en otro tipo de investigaciones pueden quedar inexplorados. La investigación etnográfica sirve para enfocar la mirada en aspectos que han sido muchas veces silenciados. Este tipo de investigación nos permite profundizar en los temas de estudio no solo a través de la recopilación de datos, sino también de sensaciones, vivencias, opiniones, discursos distintos que luego deberán ser analizados para llegar a unas conclusiones que tratarán de comprender una realidad que es heterogénea y en la que no todo es cuantificable.

Los módulos en los que se divide el curso son los siguientes: primero, un módulo introductorio en el que se explica en qué consiste el trabajo de campo etnográfico y los estudios de patrimonio; segundo, un módulo en el que se expone la necesidad de aplicar unos principios éticos dentro de cualquier investigación; a continuación, los módulos tercero, cuarto y quinto nos presentan las principales técnicas de investigación etnográfica, que son la observación participante, el diario de campo, las entrevistas, las historias de vida, el mapeo de actores y las cartografías colectivas, introduciéndonos también de manera práctica a todas ellas. Mención aparte merece la última de las técnicas que se presentan, la denominada IAP (investigación-acción participativa), que adquiere una especial relevancia en la investigación antropológica actual con un enfoque participativo. El sexto módulo

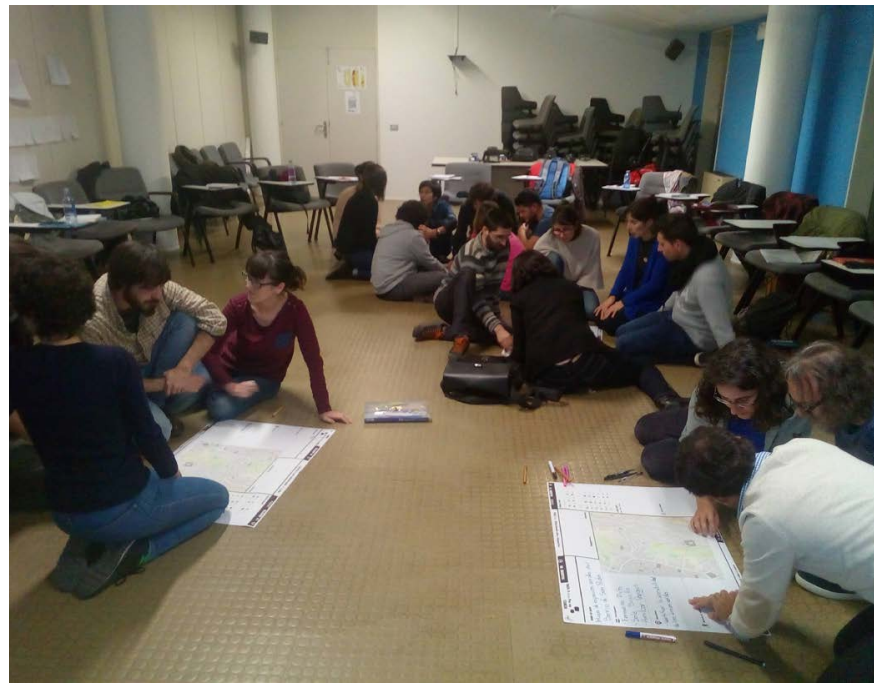

Sesión del curso dedicada al diseño de cartografías colectivas | foto Guadalupe Jiménez-Esquinas

del curso nos introduce en la antropología visual y nos explica la utilidad del uso de fuentes audiovisuales para la investigación etnográfica $y$, finalmente, el último de los módulos trata de acercar al alumnado al proceso de escritura etnográfica.

\section{INFORIMACIÓN}

La matrícula para la edición de 2017 permanecerá abierta hasta el próximo 15 de octubre.

Todos los datos en el siguiente enlace: <http://hdl.handle. net/10261/152538> 